\title{
Chapter 17 \\ Addressing Climate Change Impacts in the Sahel Using Vulnerability Reduction Credits
}

\author{
Karl Schultz and Linus Adler
}

\begin{abstract}
Adaptation projects may be difficult to prioritize and finance, as the results of projects are difficult to quantifiably measure and compare across project types, and no singular "unit" for adaptation outcomes exists. The Higher Ground Foundation is developing the Vulnerability Reduction Credit (VRC ${ }^{\mathrm{TM}}$ ), which incorporates cost/benefit analysis and per capita vulnerability equalization tools to measure the outputs of climate adaptation projects. The VRC quantifies in a singular unit measures to reduce vulnerability to climate change. This chapter summarizes the structure and utility of VRCs and shows through a case study from Talle, Niger, how VRCs are created and integrated into Sahelian community adaptations to heterogeneous climate risks such as flooding and droughts. VRC analysis and crediting may serve as a monitoring and evaluation tool and as an instrument to help secure project finance while supporting sustained adaptation. The chapter further considers the potential benefits to governments, donors and economies. VRC financing has advantages over standard development assistance models, particularly for project risk management, project preparation, enhanced transparency of adaptation spend, and scaling of successful pilot projects throughout an economy.
\end{abstract}

Keywords Vulnerability reduction credit - Adaptation finance - Sahel • Monitoring and evaluation climate adaptation - Climate resilience

K. Schultz $(\bowtie) \cdot$ L. Adler

The Higher Ground Foundation, 18 Northchurch Terrace, London, UK

e-mail: karl@climateadaptationworks.com

L. Adler

e-mail: linus@climateadaptationworks.com 


\subsection{Introduction}

Climate change is happening and it is impacting communities around the world. While all nations will be impacted by climate change, primarily for the worse, the poorest countries face the most human vulnerability.

Sub-Saharan Africa is both particularly vulnerable to climate change and lacking sufficient adaptive capacity to address many of the impacts on agriculture, the built environment, health, and other sectors. The economic impact of climate change will be considerable; by the end of the century climate change is estimated to cost $10 \%$ of Africa's GDP, and the costs of effective adaptation could be between \$US 10 billion and £UK 30 billion per year by 2030 (Pan African Climate Justice Alliance 2009). Africa will bear the highest costs per capita in terms of GDP (Watkiss et al. 2016).

In the context of planning processes, research has shown few examples of climate information being integrated into the planning of long-term development. Reasons given for this include short-term development challenges focusing decision-makers' attention on shorter timescales, a lack of both serviceable medium- to long-term climate information and integrated assessments of climate impacts, vulnerability, or adaptation, and a communication mismatch between the producers and users of climate information (Jones et al. 2015).

Although expenditures are generally viewed as insufficient, a considerable amount of adaptation investment is already taking place in developing countries. Overseas development assistance is considerable, but the traditional approach (as typified by the Paris Climate Agreement) for financing climate adaptation in developing countries is to set a global monetary target, rather than focus on vulnerability reduction as the measure of results. Unfortunately, many development assistance projects that are labelled "climate adaptation" have little to do with climate adaptation (Junghans and Harmeling 2012). Meanwhile, governments in Africa are diverting much of their own resources to address climate change; for instance, the Overseas Development Institute found that 5 and 14\%, respectively, of Tanzania's and Ethiopia's annual national budgets were spent on addressing climate change (Bird 2014). And both governmental and development assistance spend also suffers from a lack of transparency and misallocation of funds (Alabi 2012).

The role of the private sector is often taken as critical in securing sufficient finance to meet the global adaptation investment requirements. However, a major challenge for getting the private sector involved is finding sufficient justification to undertake adaptation. As rational, profit-seeking bodies, private companies may recognize the threats climate change may bring to their business, through disrupted supply chains and harm to assets and even markets. But, for these same organizations to play a role in developing or financing projects that have limited or no direct impact on corporate returns, (as is the case with many community-level adaptation projects in Africa) a revenue stream, and related price signal must be established. 
While governments might subsidize some private involvement via tenders, and while there are a number of cases where adaptation may bring clear financial returns to investors, the nature of much climate vulnerability is that, while economic returns from adaptation measures (that may be represented variously through avoided damage to buildings, etc.) are usually possible, financial returns (represented in direct project-level revenue streams) are much more difficult to achieve. This is particularly the case for adaptation projects that address the vulnerabilities of poorer communities. And so the challenge can be seen as identifying and deploying mechanisms that can convert economic need into financial investment.

When resources are allocated to adaptation, there is the risk that they may be ineffective or inefficiently invested, owing to a lack of understanding of adaptation's benefits. In part, this risk is created because of the lack of a recognized, general approach to evaluate and compare projects undertaken to reduce vulnerabilities to climate change.

\subsection{The Need for New Instruments to Address Local Vulnerabilities}

Without a mechanism that can allow projects to be compared, and potentially incentivized, that is free from local or other political considerations, many of the great adaptation challenges facing Africa will persist. With such a mechanism, in particular one that is fungible, has a single metric, and can be certified as a quantity of recognized "vulnerability reduction", it is possible to:

- Better prioritize projects (thus bringing in efficiencies that increase the potential for effectively using limited resources),

- Serve as a means for leveraging finance from the revenue streams created, by setting a price on a quantified level of vulnerability reduction,

- Allow for more transparent, "bottom-up" decision-making in adaptation investment, as communities, private and public adaptation technology and service providers, and project developers have a fair chance at gaining credits,

- Serve as a positive feedback mechanism as the "market" for adaptation technologies and effective project investment and operations improves through the incentive to optimize project vulnerability reduction.

- Create incentives for sustainable projects, as credits are issued only if projects can prove that vulnerability reduction has been ensured for a (past) period of time.

The challenges to creating such an instrument that may result in these benefits, include ensuring that it transparently, efficiently, and flexibly provides quantifiable and verifiable incentives, resulting in real and additional climate vulnerability reduction for poor communities. This entails ensuring that the instrument: 
- is robust: that baselines are clear, that projects establish that they are going beyond this baseline and that the monitoring and verification of the outputs is unambiguous,

- is quantifiable, in order to permit price setting around the units of vulnerability reduction, and to compare projects, and

- is sustained over time, which suggests a system design wherein projects are only awarded credits after the results are verified.

\subsection{Vulnerability Reduction Credits (VRC'TM)}

The proposed instrument, designed to meet the above requirements, is the climate Vulnerability Reduction Credit (VRC ${ }^{\mathrm{TM}}$ ). A VRC represents avoided impact cost, normalized with an income equalization factor. Downscaled climate projections are used to estimate increased impact costs with climate change, and projects are then assessed for how they decrease these costs. In addition, projects wishing to be awarded VRCs must meet certain social and other criteria. The VRC is a credit for work done to avoid damages or losses owing to climate change (Schultz 2012). There are three fundamental assumptions in VRC analysis that, if accepted, validate their value in measuring vulnerability reduction:

1. Economic conditions are a valid measure of human wellbeing and can proxy for adaptive capacity,

2. Economic impacts can often be quantified, and,

3. Impacts can be equalized for poorer communities.

The first assumption is that while there are many very important non-economic values, and that while economic wellbeing is not equivalent to human wellbeing, everyone needs to eat and be sheltered and economic conditions are a universal, and often easily measurable, index related to human well-being, certainly as it relates to most people living in developing countries.

The second assumption is that we can most easily assess vulnerability reduction using economic cost-benefit analysis tools, which represent an established approach (Atkinson and Mourato 2008). There are a variety of methods for monetizing non-financial values (e.g., hedonic pricing), and many of the climate vulnerabilities communities face may be easily monetized (e.g. loss in agricultural production).

The third assumption, that we can equalize impacts by factoring in per capita income, is important if equity is a consideration, or more fundamentally, if human vulnerability is the main concern rather than protection of economic assets or incomes. By considering a vulnerable community's per capita income, the VRC can take into account the reduced value, and thus economic impact, of poorer communities, focusing rather on the amount of human vulnerability per capita. 


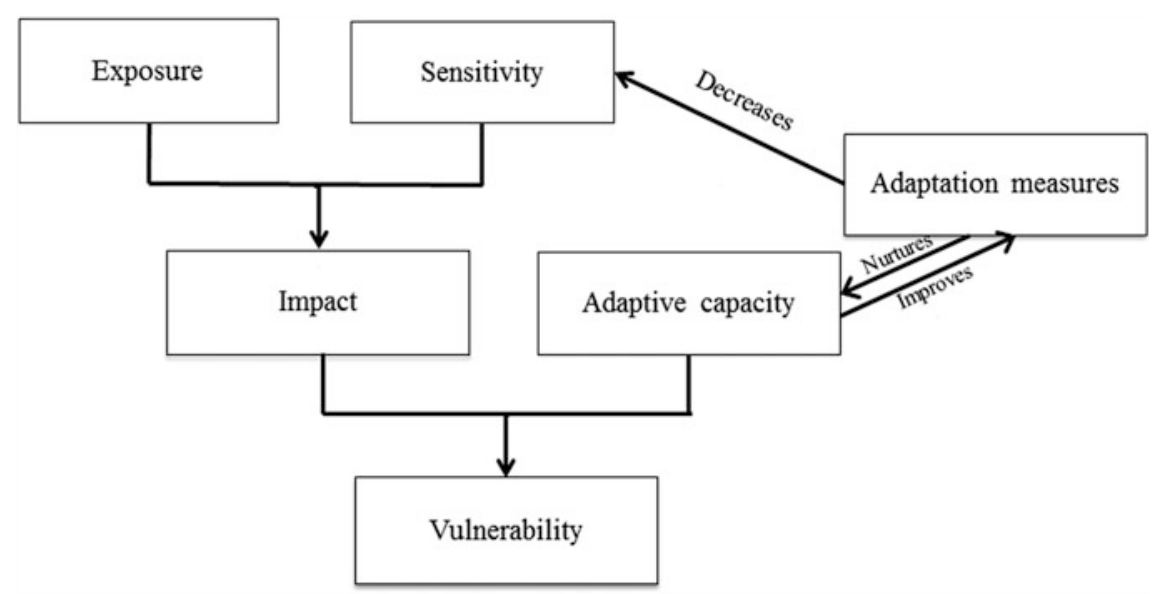

Fig. 17.1 Relationship between vulnerability, exposure, sensitivity, and adaptive capacity

The theory behind the analytical construction of VRCs is adapted from the IPCC's Fourth Assessment Report (IPCC 2007), which states that vulnerability is a function of exposure, sensitivity, and adaptive capacity. Adaptation measures decrease sensitivity and nurture adaptive capacity, and as a result vulnerability may be reduced (Fig. 17.1).

\subsubsection{How Do VRCs Work?}

Essentially, a Vulnerability Reduction Credit represents $€ 50$ of avoided impact cost. It consists of:

- The Avoided Impact Cost (AIC), and;

- An Income Equalization Factor (IEF).

Dividing the product of the AIC and the IEF by $€ 50$ gives the number of credits a project earns (Fig. 17.2):

$$
\# \text { VRCs }=(A I C \times I E F) \div € 50
$$

As discussed previously, this formulation is analogous to the IPCC's definition of climate change vulnerability as a function of Exposure (of a system to climate change), Sensitivity (of the exposed system to climate change) and the Adaptive capacity of the system.

It might be useful to further unpack the terminology in the VRC formula. The first term - the AIC - is analogous to exposure and sensitivity, which can be looked at through the lens of expected damage or loss of income. Under anticipated climate 


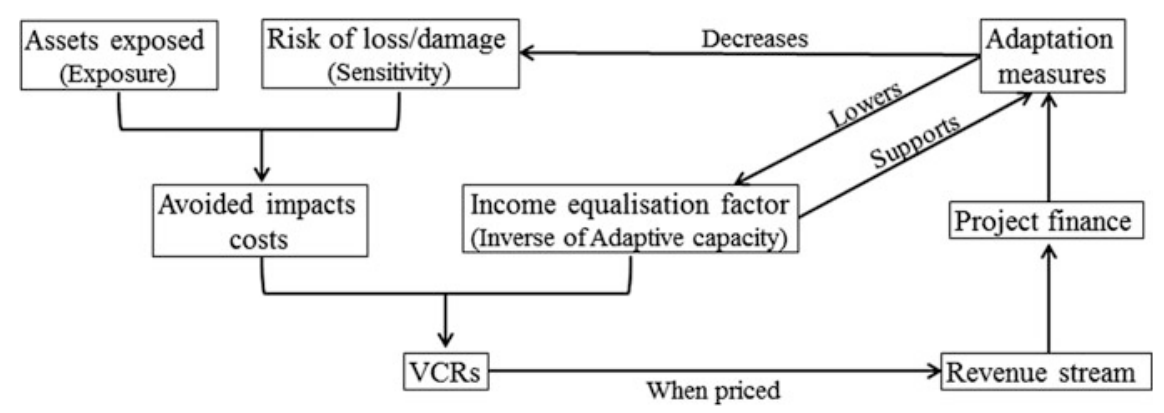

Fig. 17.2 Application of VRCs to vulnerability reduction and adaptation process (see Fig. 17.1)

change, the impact cost would be expected to go up in many circumstances. The avoided impact cost is therefore simply the expected value restored to a vulnerable system through either lessening the chance or extent of adverse climate consequences. The second term in the formulation - the IEF-is used to normalize potential project value in communities with different income levels. A project in, say, a poor village in Bhutan would be valued quantitatively differently than a similar project in, say, Colombia or the UK where avoided impact costs may be higher given the higher economic asset levels and economic productivities; this would have the distorting effect of favoring projects in wealthier communities and countries. The IEF works as follows - the local per capita income is divided into the World Bank's Gross National Lower to Upper Middle Income per capita income figure (World Bank 2016) producing a dimensionless IEF multiplier (if the per capita income is higher than the World Bank threshold figure, then the IEF is set as one). This reflects research indicating that levels of human well-being decouple from incomes as they reach this level (Wilkinson and Pickett 2009). Hence, vulnerability reduction is created and quantified based on avoided impact costs, adjusted for poorer communities by a factor inversely related to the vulnerable community's per capita income. VRC generating projects interpret and apply the relationship of different factors in reducing vulnerability, with assets exposed being the proxy for exposure, risk of loss/damage of sensitivity, and the income equalization factor the inverse of adaptive capacity (Fig. 17.2).

It's important to consider how over time VRC generation will result in enhanced adaptive capacity, as reduced vulnerability may contribute to increased per capita income and correlated enhanced capacities, including adaptation know-how, and physical resources (such as dikes, better crop varieties, etc.).

\subsection{How Do VRC Projects Work?}

In generating VRCs, a project employs a cascading chain of results projection (Fig. 17.3). 


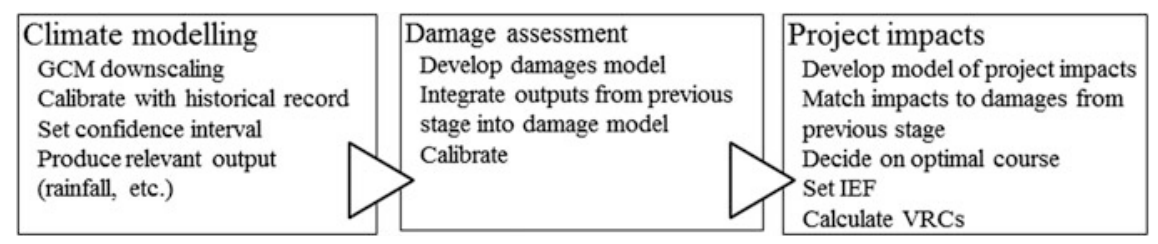

Fig. 17.3 VRC project flow

\subsubsection{Climate Modelling}

The climate modelling stage forms the basis for understanding the effects of climate change. So-called downscaled climate modelling outputs are often critical to quantifying climate factors such as rainfall and temperature in terms of their effects at a local level. Climate downscaling involves applying the outputs of one or more global models (more technically called "general circulation models", or GCMs) at their lowest scale into a downscaled regional to local model (USAID 2014; McSweeney 2010). There are a variety of dynamic and statistical modelling packages available (UK MET Office Hadley Climate Centre 2016), and while the cost of undertaking an independent model run can be considerable, the use of existing, validated model runs is permitted. As time passes, off-the-shelf modelling results suitable to a particular project's scope will be more likely to be available, although it is always necessary to verify their applicability to specific project purposes.

\subsubsection{Impacts Estimation}

Once local downscaled climate outputs have been developed or obtained, they then are used to estimate impacts. There are a wide variety of approaches to estimating impacts; to consider just two impacts from one climate output vector, rainfall projections can be used as an input in crop models or for estimating drainage, while hydrological models and civil engineering methods can be used to predict and avoid potential flooding.

\subsubsection{Modelling the Intervention}

Prior to the impacts modelling process, the project designers may have already identified or planned adaptation interventions, or this may be undertaken once the climate impacts are better understood. It is likely that a combination of the two approaches will apply; regardless, once an impact model exists, it will be possible 
to test the application of specific impacts in order to predict the reduction in vulnerability under alternative adaptation interventions. For instance, various methods for flood control or different crop substitutions or agronomical measures can be assessed for suitability. By doing this, the project developers can determine an optimal course of action and, even more importantly, produce a quantifiable blueprint for reduction in vulnerability. The VRCs generated by the project correspond therefore to the difference in net impact value from the status quo (i.e., no project, or a project that ignores expected climate change in its design).

\subsubsection{Income Equalisation}

The Income Equalisation Factor (IEF) (Sect. 17.3) is integral in the VRC issuance calculation and is an indicator of the adaptive capacity of communities. Income equalization ensures that VRCs are not exaggerated in high income communities (owing to potential damages being valued higher per capita) and, likewise, not understated in poorer communities. As such, projects must establish with confidence the current or recent past per capita income of the people living within the project boundary. To determine an appropriate project IEF, project developers can draw upon a number of sources, including approved government or third party per capita income data, or use sampling of the population within the project boundary to estimate incomes following standard approaches to remove bias.

\subsection{Applying VRCs to Local Climate Vulnerabilities}

VRCs may be used to address a number of challenges that Sahelian communities may face as they attempt to adapt to climate changes. These can be broadly divided into aiding the processes of:

- Adaptation planning and methodology development,

- Project finance, and

- Monitoring and evaluation.

These challenges cross different scales, from the very local to national and even international, and also consider the potential for involving the broadest array of potential solution providers - cities, community groups, non-governmental organizations, local private project developers, adaptation technology providers, to name some of the most important. Climate adaptation in Africa faces a number of difficulties, including that of prioritizing investments in a transparent, and ideally, effective way (Table 17.1). VRCs can be a way to plan and set targets for governments, in a diverse set of circumstances, from local allocations of public funds to submissions of nationally determined contributions that may trigger funding 
Table 17.1 Climate vulnerability challenges in Sahelian Africa

\begin{tabular}{l|l}
\hline Challenges in Sahelian context & VRC opportunities \\
\hline $\begin{array}{l}\text { Lack of fungible, quantifiable, cross-sectoral } \\
\text { means of prioritising and setting targets for } \\
\text { governments (e.g., Nationally Determined } \\
\text { Contributions) }\end{array}$ & $\begin{array}{l}\text { VRCs allow governments means of seeing } \\
\text { impacts across sectors, and determining what } \\
\text { may be most effective }\end{array}$ \\
\hline $\begin{array}{l}\text { Lack of approaches to mobilize international } \\
\text { climate finance (e.g., Green Climate Fund) }\end{array}$ & $\begin{array}{l}\text { Could create VRC buying pools and } \\
\text { encourage donors to buy VRCs }\end{array}$ \\
\hline $\begin{array}{l}\text { Challenge going from pilot project to scaling } \\
\text { for entire economies, identifying good } \\
\text { projects }\end{array}$ & $\begin{array}{l}\text { Successful pilots could be then turned into } \\
\text { national programs with VRCs the basis for } \\
\text { budgeting and evaluating }\end{array}$ \\
\hline $\begin{array}{l}\text { Lack of robust, transparent means of } \\
\text { identifying and evaluating projects }\end{array}$ & $\begin{array}{l}\text { Transparent methodologies and project } \\
\text { review/validation/monitoring and verification } \\
\text { required, linking projects with climate change }\end{array}$ \\
\hline $\begin{array}{l}\text { Lack of means to engage with private sector } \\
\text { and mobilize private finance }\end{array}$ & $\begin{array}{l}\text { If price put on VRCs, stimulates innovation } \\
\text { by private sector seeking to find (and find } \\
\text { value) in most effective vulnerability } \\
\text { reduction measures, gives revenue stream to } \\
\text { back debt/equity }\end{array}$ \\
\hline
\end{tabular}

through mechanisms such as the United Nations' Framework Convention on Climate Change's (UNFCCC's) Green Climate Fund. Funders could develop buying pools, and projects could be selected based on their potential for reducing climate vulnerabilities as reflected in the number of VRCs generated.

Such a scheme offers an opportunity for much needed private finance to be leveraged (Sect. 17.8). Pilot projects, which often are great examples of what is possible, may be difficult to replicate throughout an economy owing to insufficient access to project finance. Scaling up project types can result if a price is put on each VRC a project could be awarded.

Local community groups, NGOs, and private companies are often best suited to participate in climate adaptation projects at the local level, but may lack the funds, or the incentive to be involved in community adaptation. Through a program that prices VRCs, these groups can gain the resources required for them to act. This includes entities that have specialist skills, technologies, or resources that would otherwise have to be funded through what may be less flexible government tendering, and the private financial sector could now be directly involved in project finance as it could see a revenue stream in the anticipated issuance of VRCs.

Monitoring, evaluating (and comparing) how effective different projects, and project types, have been at reducing vulnerability, is another way VRCs may be used. The requirements of projects to develop publically available project documents and monitoring plans results in a high degree of transparency.

Project owners and beneficiaries have a direct incentive to adhere to the VRC project monitoring plan, as this is a requirement for VRC issuances. As such, VRC generating projects, especially those that secure revenue from the credits, are likely to be sustained over long periods in order to secure the maximum number of VRCs. 


\subsection{Climate Change in the Sahel and Impacts on Communities}

The Sahel (from the Arabic "sahil," meaning "coast" or "shore") is a zone of geographic, cultural, and climatic transition stretching longitudinally across the continent of Africa between the Sahara desert and the Sudanian Savanna. The region touches or covers parts of the countries of Senegal, Mauritania, Mali, Burkina Faso, Algeria, Niger, Nigeria, Chad, Sudan, South Sudan, and Eritrea over approximately $3,800 \mathrm{~km}^{2}$ (IRIN 2008) (Fig. 17.4).

The Sahel is a semi-arid region, receiving about 100-200 mm of rain annually, The region has a very rapidly growing population, which is expected to reach 100 million in 2020 and to double from there by 2050 (IRIN 2008).

The climate stresses on the Sahel region are generally defined by water (typically, the lack thereof, although, as discussed below, high precipitation can bring its own problems). The hydrology of the western part of the Sahel is dominated by the Niger River, the second-largest in terms of flow on the African continent. The region has also undergone significant fluctuation in rainfall over time, most recently in the period since 1970, which has been characterized as "the most dramatic example of inter-decadal climatic variability ever measured quantitatively on the planet since instrumental records have been kept" (Rasmussen and Arkin 1993; Grijsen et al. 2013; Hulme 2001; Redelsperger et al. 2006). Combined with the general difficulty in accurately modelling the effects of climate change on regional hydrological systems, this background natural variability makes future climate risks and stresses difficult to assess.

Modelling based on a common "baseline" global emissions scenario (closest to Representative Concentration Pathway 4.5 in IPCC's Technical Assessment Report $5,2014)$ has been found to be consistent with a projected rise in average temperatures in the Niger Basin region of between +1.0 and $+3.0^{\circ} \mathrm{C}$ by 2050 (Grijsen et al. 2013).

Rainfall, however, is highly model-specific and is predicted to either increase or decrease depending on the model, with no clear directionality of this measure seen

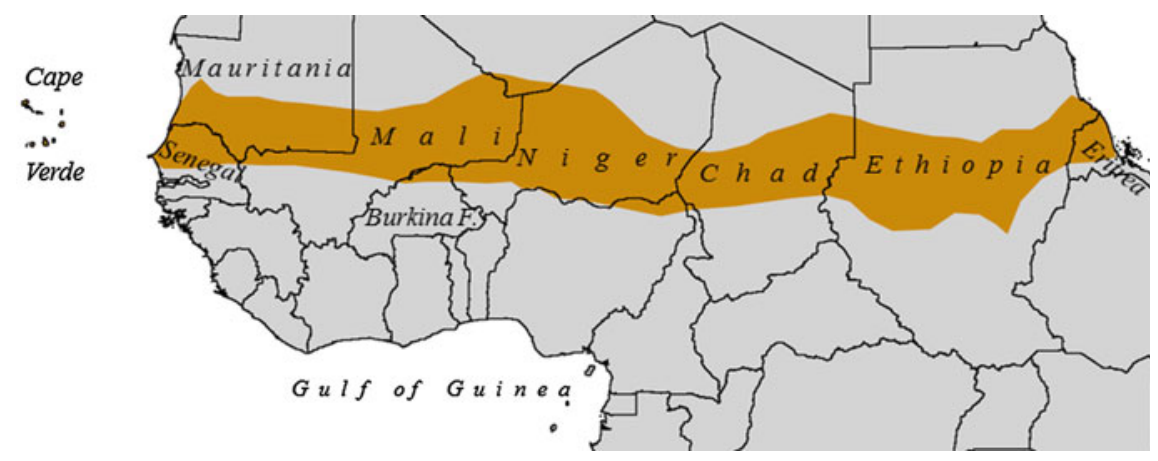

Fig. 17.4 Map showing Sahelian region in orange 
until after 2050. This suggests that, in the future, communities will have to be prepared to withstand the region's characteristically complex and fluctuating climate modalities, perhaps with more variability in terms of intensity and timing, and with a likely added temperature signal contributing to heat stress and increased evapotranspiration. Even if annual rainfall decreases or remains stable, changes in rainfall pattern and timing can lead to increased incidence of flooding events, as is already being reported in parts of the region (see next section).

Despite the potential for increased rainfall in the Sahel, many climate observers caution against an assumption that climate change is, overall, "helping" West African agriculture, noting that, aside from the added heat stress dangers owing to the anticipated temperature rise, an associated rise in evapotranspiration could negate any net hydrological gain from increased precipitation (Carbon Brief 2015). Despite their demonstrated resilience, rural populations in the region are still vulnerable to increases in variability and in recent years have begun to observe a growth in seasonable irregularity that is making it increasingly difficult to plan and carry out plantings (Thomas 2013). Other impacts likely to follow from changes in rainfall frequency, timing, and intensity include shrinking of wetlands, decrease in species variety, water quality degradation, salinization, water table reduction, and erosion (German Federal Ministry for Economic Development and Cooperation and KFW Entwicklunbbank 2010).

\subsection{A Case Study: Tillaberi}

Recently, the ANADIA project (Tarchiani and Tiepolo 2016), a collaboration between the Italian Ministry of Foreign Affairs IBIMET-CNR, DIST-Politecnico and University of Turin, and the National Meteorological Service of Niger, was active in Tillaberi Region, Niger in developing a climate risk assessment for two subsistence farming villages located on the river Sirba at a distance of about $60 \mathrm{~km}$ from the capital, Niamey (Table 17.2).

With a combined population of about 7,200, these neighboring villages have faced varying stresses in the form of increased and increasingly erratic pluvial flooding, early onset of the growing season, and drought. Although as discussed above it is particularly difficult in the Sahel region to attribute seasonal or even multi-seasonal variance in weather patterns to an overarching anthropogenic forcing signal, the projected increase in temperatures in West Africa is likely to be associated with increased chaos in regional and local weather systems.

The communities, Talle and Garbery Kourou, grow a number crops both for subsistence and market sales; the crops include millet, sorghum, rice, peanuts, and tomatoes. Per capita income is approximately $\$ 200$ per year. The villagers also maintain some livestock for subsistence and market purposes. Extreme flooding events, as have occurred in 2007, 2008, 2010, 2012, 2013, 2014, and 2015, have had severe impacts on livelihoods in both villages. Flooding in 2014 affected 60,000 people in Niger, with the worst effects occurring in Tillaberi. In that year, 38 
Table 17.2 Climate assessment (ANADIA)

\begin{tabular}{|c|c|c|}
\hline \multicolumn{3}{|l|}{ ANADIA project } \\
\hline & Case study 1: Talle & Case study 2: Garbery Kourou \\
\hline \multicolumn{3}{|l|}{ Background } \\
\hline Geographic location & $\begin{array}{l}001^{\circ} 37^{\prime} \text { 697E, latitude } 13^{\circ} \\
45^{\prime} 647 \mathrm{~N}\end{array}$ & $\begin{array}{l}001^{\circ} 36^{\prime} 589 \mathrm{E} \text {, latitude } \\
13^{\circ} 44^{\prime} 431 \mathrm{~N}\end{array}$ \\
\hline Population & 2603 (2012), 2235 (2001) & 4634 (2012), 3990 (2001) \\
\hline Families & 372 & 520 \\
\hline People per family & 7 & 9 \\
\hline Distance from the capital & About $57 \mathrm{~km}$ & About $59 \mathrm{~km}$ \\
\hline Main economic activities & Agriculture and livestock & Agriculture and livestock \\
\hline $\begin{array}{l}\text { Population perception of } \\
\text { climate change }\end{array}$ & Seasons arriving early & Seasons arriving early \\
\hline Geographic location & $\begin{array}{l}001^{\circ} 37^{\prime} \text { 697E, latitude } 13^{\circ} \\
45^{\prime} 647 \mathrm{~N}\end{array}$ & $\begin{array}{l}001^{\circ} 36^{\prime} 589 \mathrm{E} \text {, latitude } \\
13^{\circ} 44^{\prime} 431 \mathrm{~N}\end{array}$ \\
\hline \multicolumn{3}{|l|}{ Climatic data } \\
\hline Rain per year & $530 \mathrm{~mm}(2012) ; 441$ (2014) & $530 \mathrm{~mm}(2012) ; 441$ (2014) \\
\hline $\begin{array}{l}\text { Extreme events that have } \\
\text { affected the area }\end{array}$ & $\begin{array}{l}\text { Flooding 1966, 1987, 2008, } \\
\text { 2012, } 2013\end{array}$ & $\begin{array}{l}\text { Flooding 1959, 1987, 2007, } \\
\text { 2010, 2012, } 2013\end{array}$ \\
\hline $\begin{array}{l}\text { Climatic variations in recent } \\
\text { years }\end{array}$ & Seasons arriving early & Seasons arriving early \\
\hline \multicolumn{3}{|l|}{ Agricultural data } \\
\hline $\begin{array}{l}\text { Type of agriculture } \\
\text { (subsistence, sale, etc.) }\end{array}$ & Subsistence, local market & Subsistence, local market \\
\hline Main products cultivated & $\begin{array}{l}\text { Millet, sorghum, rice, } \\
\text { peanuts, tomatoes }\end{array}$ & $\begin{array}{l}\text { Millet, sorghum, rice, peanuts, } \\
\text { tomatoes }\end{array}$ \\
\hline Soil type (sand, clay, etc.) & Dune, clay and rocky & Dune, clay and rocky \\
\hline $\begin{array}{l}\text { Agricultural equipment } \\
\text { available }\end{array}$ & Animal traction & Animal traction \\
\hline Method of irrigation & Californian, watering can & Californian, watering can \\
\hline $\begin{array}{l}\text { Methodology for collecting } \\
\text { water }\end{array}$ & Adaptation measure & Adaptation measure \\
\hline Main agricultural challenges & Runoff & Runoff \\
\hline
\end{tabular}

people died as a direct result of the flooding, which also helped contribute to a cholera outbreak following the summer rainy season. The following year, more than 20,000 people were affected by flooding (Floodlist 2015). One major impact of flooding events is damage/destruction to houses and related built infrastructure. As in many West African villages, the residential and commercial housing stock of Talle and Garbery Kourou are primarily of an inexpensive mud type characterized (albeit in a more elaborate manner) by the distinctive "digging banco" mud architecture seen in Timbuktu. ANADIA divided the communities' housing into two typologies: the simpler "maisons en banco" ("houses of mud"); and "maisons semi-dur" ("semi-durable" or hardened structures). Maison banco structures are 
particularly susceptible to complete damage in flooding events and rebuilding has become a major cost factor in the wake of recent floods. ANADIA has characterised potential damages in a typical flood reaching up to approximately one-third of the real estate value in an affected community: in the case of Talle and Garbery Kourou, for instance, this would amount to a 20-year expected loss of value of more than 30 million CFA (51,000 USD). An increased incidence of flooding events with climate change might eventually multiply this expected annual loss several times.

\subsubsection{Approaches to Mitigating Climate Damage}

To protect village structures and crops from flooding events, ANADIA proposed several earthwork measures (Table 17.3).

- Cordons pierreux - (“stone barriers") are a simple, flexible, and efficient method for water and soil control. Essentially, the cordon pierreux is a double line of fitted stones following a curved arc. This low-tech infrastructure can be quickly put into place and can help in reducing erosion, retaining water, and maintaining soil organic content.

- Gabions - These are embankments composed of rocks bound by or piled within cage structures that slow but do not stop water flow; they serve the dual purpose of controlling flood action while conserving water by permitting it infiltrate into the ground.

- Demi-lunes-Demi-lunes, or "half-moon" catchments, are semi-circular areas of dug-out terrain used to concentrate rainfall. This technique is used primarily for increasing pasture production, rehabilitation of degraded land, and crop production (although the latter use is not common in Niger).

- Banquettes-Banquettes are raised "benches" or dikes of terrain that are also useful for concentrating rainfall in order to assist planting and concentrate soil nutrients.

Table 17.3 Potential ANADIA adaptation measures and costs (ANADIA)

\begin{tabular}{|c|c|}
\hline Proposed and current adaptation measures & Costs (US\$)/unit (if available) \\
\hline \multicolumn{2}{|l|}{ Single cost structural measures } \\
\hline 1. Gabions (gabion) & 250/unit \\
\hline 2. Cordons pierreux (stone barriers) & $65 / 200 \mathrm{~m}$ \\
\hline 3. Demi-lunes (half-moon catchments) & 230/ha \\
\hline 4. Plantations & 1100/ha \\
\hline 5. Banquettes (dikes) & $500 / \mathrm{ha}$ \\
\hline 6. Building upgrades (mud houses to semi-durable) & 4000/structure \\
\hline
\end{tabular}

Only the simplest of these measures (i.e., cordons pierreux) have been developed by local people; others are implemented by international organizations 
In addition, most village dwellings are currently of the less sturdy maisons en banco type. To reduce potential catastrophic damage and cleaning costs during flooding events, structures can be rebuilt in the more permanent semi-dur style at an approximate cost of $\$ 4,000$ for a typical family dwelling.

While some of these measures have already been adopted in the villages, there exist capital and institutional barriers that have prevented them from autonomously adopting the optimal range of adaptation measures. Although demi-lunes, for example, are a demonstrated technology for regenerating soil and containing rainfall, they have so far not been taken up autonomously at scale in Africa (UNEP 2016). This might be a result of cost, as the UNEP reports that demi-lune installation costs the equivalent of $\$ 150 /$ ha to construct (ibid.); given how high this figure is relative to the typical per capita income of the region (ca. \$100-200), this represents a significant barrier to autonomous implementation.

Changes and augmentation to the current crop mixture may also be necessary in order to maintain productivity as the growing season changes both in terms of increasing daily maximum and monthly average temperatures and increasingly erratic hydrological conditions.

Other potential adaptations include institutional measures such as the development of early-warning weather systems, awareness training, and the delimitation of flood zones. While such interventions are much less physically capital intensive, they require investments in intangible, time-intensive factors such as human expertise, research, policy/planning formulation, and institutional development that have to be maintained and augmented over the project lifetime and thus entail more significant recurring costs.

\subsubsection{Converting Vulnerability into Adaptation: Producing VRCs in Tillaberi}

The alternatives outlined above to mitigating climate-related damages in communities such as Talle and Garbery Kourou are generally not difficult to implement, but they require capital investments that could prove prohibitive. In the case of the Tillaberi ANADIA project, for instance, initial estimates based on the cost elements amount to an initial capital investment of approximately $€ 800,000$ plus recurring annual operation and maintenance costs of more than $€ 2,000$ per year over a $20+$ year project lifetime. Given the low income level of the communities and the current lack of access to capital markets, such cost levels are a barrier to implementation. The ANADIA project study, for example, concluded that measures for reducing risk to the villages of Talle and Garbery Kourou by up to $23 \%$ would cost from $€ 23$ to 34 per capita (out of a per capita income of c. $€ 160$ ), representing an "unsustainable" expenditure for rural families or the municipalities. (Tiepolo and Braccio 2017). 


\subsubsection{VRC Registration, Certification, Issuance, and Monitoring}

Using a VRC ${ }^{\mathrm{TM}}$ calculator, potential VRCs were estimated (Tables 17.3 and 17.4) for a project in the villages of Talle and Garbery Kourou, Niger. In this case, the VRC analysis centred specifically on measures that protect against river flooding, with interventions consisting of items 1-5 (Table 17.3) for crop and infrastructure protection via water flow control and enhanced irrigation and item 6, representing an investment in more flood-resistant village structures. Note that this represents an indicative case and that, while it relies on some figures reported by the ANADIA project, estimates of many of the driving climate factors have been made for illustrative purposes. Essentially, the calculations can be broken into three scenarios for comparison. The first scenario, labelled "Baseline" (Table 17.4), represents a continuation of the conditions in the first year of the project with a small expected growth in village size and output added to represent change in conditions assumed if the overall climate conditions did not change from that of the first project year. These calculations are useful for comparison with the indicative effects of climate change, as shown in the "Climate Change Scenario" section (Table 17.4), which represents the true project baseline with no actions taken specifically to adapt to anticipated enhanced climate damage (in this case, increased incidence of flooding of the Sirba river).

Table 17.4 ANADIA project sheet showing climate scenarios

\begin{tabular}{|c|c|c|c|c|c|}
\hline & 2018 & 2019 & 2020 & $\ldots$ & 2037 \\
\hline \multicolumn{6}{|l|}{ Baseline } \\
\hline Total crop income CFA*000 & 272,090 & 275,894 & 279,774 & & 364,512 \\
\hline \multicolumn{6}{|l|}{ Capital loss costs } \\
\hline Building repair cost CFA $* 000$ & 340 & 340 & 340 & 0 & 368 \\
\hline Grand total CFA*000 & 271,750 & 275,554 & 279,434 & & 364,144 \\
\hline Exchange rate $\mathrm{CFA}^{*} 000 / €$ & 666.7 & 666.7 & 666.7 & & 666.7 \\
\hline Grand total $(€)$ & 408 & 413 & 419 & & 546 \\
\hline \multicolumn{6}{|l|}{ Climate change scenario } \\
\hline Total crop income CFA*000 & 218,270 & 222,635 & 227,088 & & 324,338 \\
\hline \multicolumn{6}{|l|}{ Capital loss costs } \\
\hline Building repair cost CFA $* 000$ & 1020 & 1020 & 1020 & 0 & 1104 \\
\hline Total net income CFA*000 & 217,250 & 221,615 & 226,068 & & 323,233 \\
\hline Exchange rate w/€ & 666.7 & 666.7 & 666.7 & & 666.7 \\
\hline Grand total $\left(€^{*} 000\right)$ & 326 & 332 & 339 & & 485 \\
\hline \multicolumn{6}{|l|}{ Project implementation } \\
\hline Total crop income CFA*000 & 290,030 & 295,831 & 301,747 & & 430,969 \\
\hline \multicolumn{6}{|l|}{ Capital loss costs } \\
\hline Building repair cost & 257 & 257 & 257 & 0 & 279 \\
\hline Grand total & 289,773 & 295,573 & 301,490 & & 430,691 \\
\hline
\end{tabular}


Table 17.4 (continued)

\begin{tabular}{|c|c|c|c|c|c|}
\hline & 2018 & 2019 & 2020 & $\ldots$ & 2037 \\
\hline Exchange rate $\mathrm{w} / €$ & 666.7 & 666.7 & 666.7 & & 666.7 \\
\hline Grand total $(€ * 000)$ & 435 & 443 & 452 & & 646 \\
\hline $\begin{array}{l}\text { Post project aggregate productivity } \\
\left(€^{*} 000\right)\end{array}$ & 435 & 443 & 452 & & 646 \\
\hline Net productivity change $(€ * 000)$ & 82 & 81 & 80 & & 61 \\
\hline \multicolumn{6}{|l|}{ Income equalization factor } \\
\hline Average per capita income $(\mathrm{CFA} * 000)$ & 731 & 742 & 752 & & 980 \\
\hline Exchange rate $\$ / C F A$ & 0.0020 & 0.0020 & 0.0020 & 0 & 0.0020 \\
\hline Average per capita income $(\$)$ & 183 & 185 & 188 & 0 & 245 \\
\hline $\begin{array}{l}\text { Lower middle income threshold } \\
\text { (GNI) (\$) }\end{array}$ & 4085 & 4085 & 4085 & & 4085 \\
\hline Income equalization factor & 22.34 & 22.34 & 22.34 & $\#$ & 16.68 \\
\hline $\begin{array}{l}\text { Monetized vulnerability reduction } \\
\left(€^{*} 000\right)\end{array}$ & 82 & 81 & 80 & & 61 \\
\hline $\begin{array}{l}\text { Total income equalized vulnerability } \\
\text { reduction }(€ * 000)\end{array}$ & 1826 & 1807 & 1788 & $\ldots$ & 1023 \\
\hline
\end{tabular}

Italics $=$ negative cash flows

$* 000=$ units of 100,000

The third scenario, "Project Implementation" (Table 17.4) shows the effects (reduced damages) based on the implementation of the project, as outlined above. The data and results are compared in a parallel manner in a year-by-year manner (from 2018 to 2037 in this case). Based on the apparent crop income per capita, the IEF-Income Equalization Factor is calculated, with the income adjusted vulnerability reduction calculated (Table 17.4) as the product of the IEF and the adaptation-related reduction in impact costs. Costs and revenues gives a break-down of capital and operating expenses for the project. The section under "Management Costs and VRC" (Table 17.5) lists project administrative and VRC registration costs, while "Physical project incremental. "Net Cash Flow" row demonstrates the funding barrier to project implementation, with a net negative balance in the initial years owing to investment and setup costs (as well as VRC registry costs). However, as the project begins earning VRCs starting in the third year of operation, the balance sheet becomes positive. Indeed, a net present value analysis over a 20-year lifetime at a reasonable social discount rate of $3 \%$ produces an added discounted project value of approximately $€ 2.6$ million, which, given an IEF of 22, equates to the generation of approximately 1,200,000 VRCs.

As for the financial results of the project (Table 17.6), the calculated 20-year climate damage is given by comparing the second with the first rows, and the effects of implementing the project are given by comparing the third with the second row - the avoided impact cost of about 2.6 million Euros compares favorably with the project costs. Note that the revenue stream here assumes a price per VRC sold of $€ 5$; given the break-even cost of $€ 1.82$ per VRC based on the project costs; this indicates a plausible investment. 
Table 17.5 ANADIA Project sheet project costs and cash flows

\begin{tabular}{l|r|r|r|r|r}
\hline & 2018 & 2019 & 2020 & $\ldots$ & 2037 \\
\hline VRCs generated, VRC management costs and VRC pricing & 50 & & & & \\
\hline Nominal VRC value $(€)$ & 0 & 32 & 32 & & 32 \\
\hline VRCs/year*000 & 0 & 5 & 5 & & 5 \\
\hline VRC monitoring costs $€ * 000$ & 50 & & & & \\
\hline PDD + validation $€ * 000$ & 0 & 5 & 5 & & 5 \\
\hline Verification $€ * 000$ & 10 & 0 & 0 & & 0 \\
\hline Registration fee $€$ & 0 & 11 & 11 & & 11 \\
\hline Issuance fee $(@ 0.35 € /$ VRC), $€ * 000$ & 60 & 21 & 21 & & 21 \\
\hline Total investor VRC generation costs $€$ & 5 & & & & \\
\hline VRC price $(€)$ & 0 & 159 & 159 & & 159 \\
\hline VRC income $€ * 000$ & & & & & \\
\hline Physical project incremental costs and revenues & 2 & 2 & 2 & & 2 \\
\hline Project incremental physical O and M costs $€ * 000$ & 23 & 53 & & & \\
\hline Project CAPEX structure protection $€ * 000$ & 374 & 374 & & & \\
\hline Project CAPEX crop measures & 426 & 426 & & & \\
\hline Project CAPEX $€ * 000$ & 82 & 81 & 80 & & 61 \\
\hline Revenue productivity savings $€ * 000$ & 62 & 23 & 23 & & 23 \\
\hline Project costs $€ * 000$ & 488 & 209 & 216 & & 197 \\
\hline Net cash flow $€ * 000$ & & &
\end{tabular}

Italics = negative cash flows

$* 000=$ units of 100,000

Table 17.6 ANADIA VRC generation figures totals (see Tables 17.3 and 17.4)

\begin{tabular}{l|l}
\hline Scenario & $\begin{array}{l}\text { Total discounted net income/worth over 20 years } \\
(\text { discount rate }=3 \%)\end{array}$ \\
\hline $\begin{array}{l}\text { No climate change, no project } \\
€ \cdot 000\end{array}$ & 9403 \\
\hline $\begin{array}{l}\text { Climate change, no project (V0) } \\
€ \cdot 000\end{array}$ & 7951 \\
\hline $\begin{array}{l}\text { Climate change, with project (V1) } \\
€ \cdot 000\end{array}$ & 10,600 \\
\hline Costs and benefit elements & \\
\hline Project costs & 2155 \\
\hline AIC $€ \cdot 000$ & $(\mathrm{~V} 1)-(\mathrm{V} 0)=2648$ \\
\hline Initial IEF & $22[$ based on initial p.c. income of $\$ 183]$ \\
\hline No. of VRC's & $(\mathrm{AIC} \cdot \mathrm{IEF}) / € 50=1,183,246$ \\
\hline Project cost per VRC $€ \cdot 000$ & $2155 / 1183=€ 1.82 / \mathrm{VRC}$ \\
\hline $\begin{array}{l}\text { Breakeven: VRC price of } € 1.82+ \\
\text { required }\end{array}$ & \\
\hline
\end{tabular}


Such analysis helps assure that the generation of VRCs by a project equates to tangible creation of climate adaptation value. The VRCs produced by the implementation of verifiable, measurable adaptation measures in Tillaberi provide potential investors with an inducement to invest in these measures. The priced VRC streams produced by the project help enable it by, for example, serving as collateral to help secure a loan to cover capital costs.

\subsection{Direct Benefits to Vulnerable Communities}

The benefits of undergoing the above process can be considerable, and possibly transformational for the vulnerable community. By itself, of course, going through the rigor of establishing a clear and quantified vulnerability baseline, understanding how a project may reduce these vulnerabilities, and setting in place a clear monitoring framework will take time and possibly considerable expense. However, both the knowledge gained and made transparent, and the potential for VRC generation may provide a vulnerable community with:

- Enhanced Adaptive Capacity: A much better understanding of the community's climate adaptation needs, and improved community decisions on the technologies, practices and timing for investment, and

- A way for the community to secure project finance that is aligned with its interests in sustained vulnerability reduction.

The vulnerable community (along with possible development partners) are able to understand and then articulate their needs through developing a VRC baseline and being able to assess the expected results (in terms of VRCs, and by extension of vulnerability reduction) of different project alternatives. In our case study, this occurs through the clear quantification of the expected economic impacts of flooding and agricultural loss through both flooding and increased droughts. The community can then identify where the most vulnerable assets are found, and focus on identifying measures (in the ANADIA project case, for example, this involves the implementation of water control infrastructure, such as demi-lunes, that would not be constructed without outside funding, and the adoption of crop switching and planning technologies) that will reduce these vulnerabilities. While the community is free to prioritize however it wishes, it receives VRCs in proportion to the amount of avoided impacts resulting from adaptation.

As such, the community can use this clear and quantifiable understanding of its vulnerabilities as both a decision-making tool and to articulate their needs and justify donor funding. Once a community knows what particular levels of vulnerability it has in different assets and production areas (in this case, crop production and buildings/crop losses), it can seek adaptations that are most appropriate and will offer the most effective results, and though the process of developing a project document understand which will be most cost effective. 
Donors will then be able to engage with the community and its adaptation partners, with the community able to describe and justify its proposed interventions.

What is perhaps the most innovative result that VRCs can offer, once a community and its partners have registered their project, is that they can then "sell" the potential vulnerability reduction to a government or donor. The vulnerability, and its reduction, transitions into being an asset for the community in its engagement with funders, and, most critically, it can offer funders a clear and relatively de-risked means of offering contingency-based finance.

There are a variety of possible financing structures that VRC generating projects could lend themselves to, with perhaps the simplest being a conventional project finance model. In this scenario, a community (perhaps aided by a project developer with technical, financial, and project development resources) would offer a donor (which could be any public or private body with an interest in reducing the community's vulnerability) to transfer some or all of its VRCs generated in return for a price per VRC. With a signed purchase agreement, the project could then go to a bank or other investor (public or private) that could then assess the project risks (noting that the community has a direct stake and incentive to reduce its own vulnerability), and offer finance.

Finally, the process of undertaking a VRC generating project can result in greater adaptive capacity as the community has tools and more immediate incentives to improve its "climate resilience". The community can profit from the priced VRCs, incentivizing a greater awareness of how to best reduce its vulnerability,

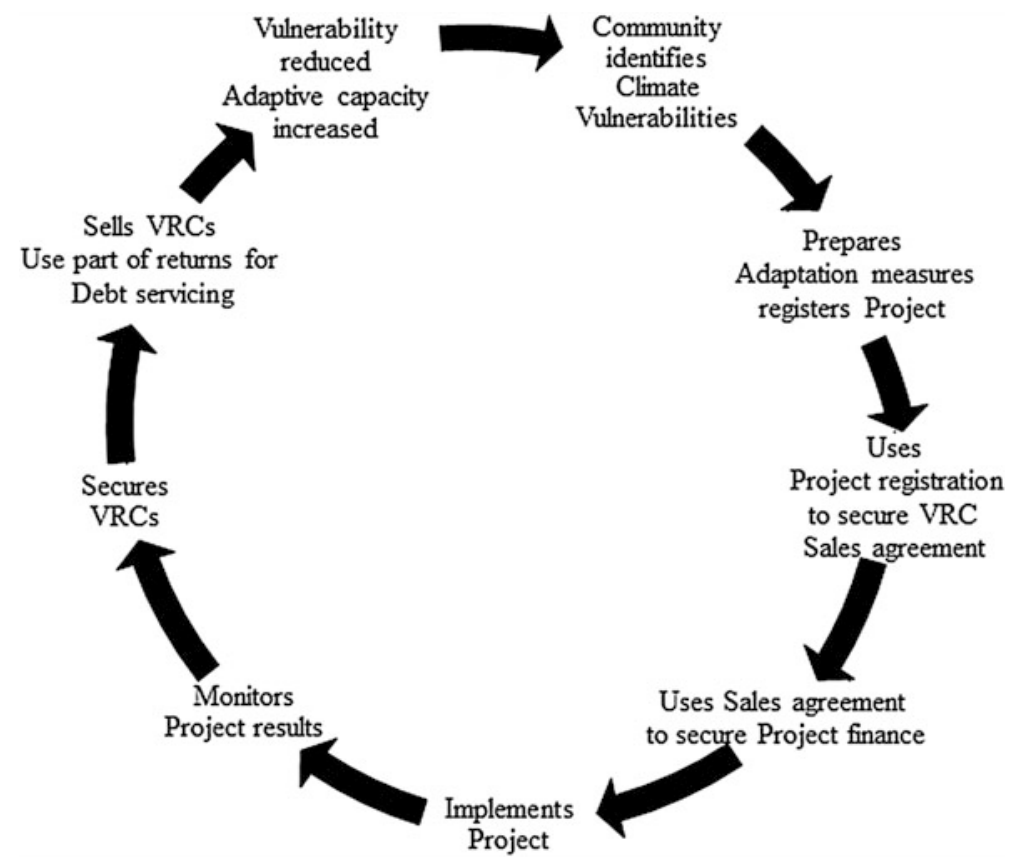

Fig. 17.5 A potential process for using VRCs to leverage project finance for climate adaptation 
taking away the possibly long-off, uncertain, and thus maybe perceived to be less real threat of climate change, to be replaced with a knowledge that its adaptation actions can bring results in a growing season through VRC sales. In turn, incomes may increase, and this, as noted above, is a proxy for and can correlate with an improved adaptive capacity (Fig. 17.5).

\subsection{Conclusion}

Climate Vulnerability Reduction Credits $\left(\mathrm{VRCs}^{\mathrm{TM}}\right)$ offer communities, donors, and governments in the Sahel and around the world with a process that can help overcome a number challenges related to effective climate adaptation. As the case study shows, VRCs offer to provide a needed source of funds and expertise to local communities, while helping donors and governments deliver scalable, transparent and capacity growing vulnerability reduction where it is needed most. There is considerable work required, however, to encourage adoption of the VRC.

\section{References}

Alabi, R.A. 2012. Sectoral analysis of impact of foreign aid in Nigeria: A dynamic specification. Downloaded on 3 June 2016 at http://www.iwim.uni-bremen.de/Siakeu/Alabi-SECTORAL\% 20ANALYSIS\%20AID-AvH-3-2012.pdf.

Atkinson, G., and S. Mourato. 2008. Environmental cost-benefit analysis. Annual Review Environment and Resources 33 (1): 317-344. doi:10.1146/annurev.environ.33.020107.112927.

Bird, N. 2014. Fair share: Climate finance to vulnerable countries. London: Overseas Development Institute.

Carbon Brief. (2015 July). Retrieved from carbon brief: http://www.carbonbrief.org/factcheck-isclimate-change-helping-africa.

Floodlist. 2015. Retrieved from http://floodlist.com/africa/niger-floods-4-dead-1000s-displaced.

Grijsen, J.G., C. Brown, A. Tarhule, and Y.B. Ghile. 2013. Climate risk assessment for water resources development in the Niger river basin part I: Context and climate projections.

German Federal Ministry for Economic Development and Cooperation (BMZ) and KfW Entwicklungsbank. 2010. Adaptation to climate change in the upper and middle Niger river basin. https://www.icafrica.org/en/knowledge-publications/article/adaptation-to-climatechange-in-the-upper-and-middle-niger-river-basin-172/

Hulme, M. 2001. Climatic perspectives on Sahelian desiccation: 1973-1998. Global Environmental Change 11 (1): 19-29. doi:10.1016/S0959-3780(00)00042-X.

IPCC. 2007. Contribution of working group II to the fourth assessment report of the intergovernmental panel on climate change. In eds. M.L. Parry, O.F. Canziani, J.P. Palutikof, P.J. van der Linden, and C.E. Hanson. Cambridge, UK and New York: Cambridge University Press.

IRIN. 2008. Backgrounder on the Sahel, West Africa's poorest region. http://www.irinnews.org/ feature/2008/06/02.

Jones, L., et al. 2015. Promoting the use of climate information to achieve long-term development objectives in Sub-Saharan Africa: Results from the future climate for Africa scoping phase. London: CDKN and Future Climate for Africa. 
Junghans, L., and S. Harmeling. 2012. Different tales from different countries, a first assessment of the OECD adaptation marker. Germanwatch Briefing Paper, September.

KFW Entwicklungsbank. 2010. Adaptation to climate change in the upper and middle Niger river basin: River Basin Snapshot. Draft for discussion: http://ccsliccip.net/niger_river_basin.pdf.

McSweeney, R.J. 2010. Selecting members of the 'QUMP' perturbed-physics ensemble for use with precis. UK Met Office: http://www.metoffice.gov.uk/media/pdf/e/3/SelectingCGMsToDownscale. pdf.

Pan African Climate Justice Alliance. 2009. The economic cost of climate change in Africa.

Rasmussen, E.M., and P.A. Arkin. 1993. A global view of large-scale precipitation variability. Journal of Climate 6: 1495-1522. doi:10.1175/1520-0442(1993)006<1495:AGVOLS $>2.0$. $\mathrm{CO} ; 2$.

Redelsperger, J.L., Thorncroft, C., Diedhiou, A., Lebel, T., Parker, D. and Polcher, J. (2006). African monsoon multidisciplinary analayis: An international project and field campaign. Bulletin of the American Meteorological Society 87 (12): 1739-1746. doi: 10.1175/BAMS-87-12-1739

Schultz, K. 2012. Financing climate adaptation with a credit mechanism: Initial considerations. Climate Policy 12 (2): 187-197. doi:10.1080/14693062.2011.605563.

Tarchiani, V., and M. Tiepolo. 2016. Risque et adaptation climatique dans la région Tillabéri, Niger. Pour renforcer les capacités d'analyse et d'évaluation. Paris: L'Harmattan.

Thomas, A. 2013. Sahel villagers fleeing climate change must not be ignored. The Guardian, August 2.

Tiepolo, M., and S. Braccio. 2017. Local and scientific knowledge in multirisk assessment for rural Niger. In Renewing local planning to face climate change in the tropics, eds. M. Tiepolo, A. Pezzoli, and V. Tarchiani. Springer.

UK Met Office Hadley Climate Centre. 2016. An introduction to the PRECIS system.

UNEP-United Nations Environment Program. 2016. Sourcebook of alternative technologies for freshwater augmentation in Africa: 1.1.2 Demi-lunes or semi-circular hoops. Newsletter and Technical Publications: http://www.unep.or.jp/ietc/Publications/TechPublications/TechPub-8a/ hoops.asp.

USAID. 2014. A review of downscaling methods for climate change projections. Washington, DC: USAID.

Watkiss, P. et al. 2016. The costs of adaptation. In The adaptation finance gap report 2016. Nairobi: United Nations Environment Programme. http://web.unep.org/adaptationgapreport/ sites/unep.org.adaptationgapreport/files/documents/agr2016.pdf.

Wilkinson, R., and K. Pickett. 2009. The Spirit Level: Why equality is better for everyone. London: Penguin Press.

World Bank. 2016. World Bank country classifications. http://data.worldbank.org/about/ countryclassifications.

Open Access This chapter is licensed under the terms of the Creative Commons Attribution 4.0 International License (http://creativecommons.org/licenses/by/4.0/), which permits use, sharing, adaptation, distribution and reproduction in any medium or format, as long as you give appropriate credit to the original author(s) and the source, provide a link to the Creative Commons license and indicate if changes were made.

The images or other third party material in this chapter are included in the chapter's Creative Commons license, unless indicated otherwise in a credit line to the material. If material is not included in the chapter's Creative Commons license and your intended use is not permitted by statutory regulation or exceeds the permitted use, you will need to obtain permission directly from the copyright holder.

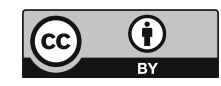

